\title{
Research on Innovation of Financial Management Model Based on Cloud Computing
}

\author{
Song yang* \\ Wuhan University of Technology, Wuhan, China
}

\begin{abstract}
Against the background of the rapid development of big data and big data analysis technologies, cloud computing service providers provide services to enterprises and individuals. In many large enterprises, by setting up a cloud computing platform environment, multiple services within the enterprise are placed on the cloud platform to provide resource sharing services for various departments. With the dramatic improvement in computing performance of computer clusters, big data and cloud computing technologies are maturing. We combine cloud computing with financial management services, and use modern technical means to innovate financial management models; we will change the financial management model of enterprises by building financial sharing service centers, thereby providing more efficient financial management services. Based on the research of cloud computing technology, this paper expounds the application of cloud computing in financial sharing, and explores the transformation of financial management models in the context of cloud computing. Fully clarify the principles and procedures for the construction of financial sharing service centers based on cloud computing, and discuss the basic structure of financial cloud management. Finally, we discuss the operation model of financial management based on cloud computing to provide a reference for researchers in financial management.
\end{abstract}

\section{Introduction}

In the context of economic globalization, innovation is an important driving force for economic development, and taking the lead in innovation can be in an advantageous position in development. The development trend of world economic integration is becoming increasingly apparent, and the scale of enterprises is constantly growing, and many large enterprise groups have emerged. The transnational and cross-regional operations of enterprises have developed rapidly, and market competition has become increasingly fierce. With the increasing number of branches around the world, the internal management and control of enterprises have become more complicated. Financial management is the core and lifeblood of business operations. In order to adapt to new changes, the financial management model needs to be changed. The new financial management model needs to be able to strengthen the control of various subsidiaries and reduce costs through the standardization and standardization of business processes. The development of computer information technology and advances in cloud computing and big data-related technologies have made financial shared service centers widely used.

In the process of enterprise development, innovative financial management models are needed.
Comprehensive domestic and foreign financial management experience, centralized management of financial core business, divest non-core business, rectify and merge these businesses, and achieve resource sharing. The rapid development of computer information technology, the continuous improvement of the Internet platform, and the ability of cloud computing to process data at high speed have created basic conditions for financial sharing. In the new era, the construction of financial shared service centers has become one of the main ways for enterprises to respond to new challenges.

Multinational companies use Internet information technology to build financial shared service centers to solve problems such as corporate management and work efficiency. Financial sharing uses a new perspective to transform the original financial process using computer technology. Under the new service model, it sorts out and combines simple and repetitive financial tasks to unify management standards and realize financial information sharing.

\footnotetext{
*Corresponding author's e-mail: songyangwhlgdx@126.com
} 


\section{Big data, cloud computing overview and financial cloud}

\subsection{Big data and cloud computing overview}

Big data has obvious characteristics and is also called massive data. With the advancement of Internet technology, the Internet is widely used in various industries, and a large amount of data is generated every day. This data is continuously accumulated to form a big data environment. Cloud computing and big data are inseparable. Big data provides a data foundation for cloud computing, and cloud computing provides a good technical environment for big data. Big data and cloud computing related technologies are developed in concert to perform data analysis and provide data references for economic management. Cloud computing is a computing model that provides services through the Internet. Cloud computing is based on the Internet and virtual technologies. It provides users with virtualized resources and data. Depending on the resources provided by the cloud, it can be divided into IaaS, SaaS, PaaS and IlaaS. Users access and use cloud resources through the Internet, and only need to pay for the use of cloud resources. For the construction and maintenance of cloud resources, the internal deployment and structure of cloud resources need not be concerned. Utilize cloud computing and use distributed computing to obtain storage and computing capabilities, replacing local computers or remote servers.

Cloud computing integrates server clusters, highly reliable IDCs, and various applications. The system implements automated management to provide IT services to customers. The main characteristics of cloud computing include the following aspects: cloud computing has a resource sharing pool, the information system integrates, classifies, and outputs various resources, and outputs related information according to different instructions; Cloud computing performs selfdata calculation without human operation; cloud computing outputs services to the outside in a unified manner, and users access the cloud as needed, and are divided into application services, infrastructure services, and platform services according to the required service level; The computing access function is extensive, allowing multiple terminals to access through standard mechanisms.

\subsection{Financial management model based on cloud computing in the context of big data}

In the context of big data, cloud computing technology realizes resource sharing through the Internet and virtual technologies. Centralizing all resources in the cloud storage center can provide powerful data processing and data storage services for enterprise users. Enterprise users only need to use simple terminal devices, purchase the service, and enjoy the storage resources and data processing functions provided by cloud computing services through the Internet. The enterprise's data information center will run on the Internet. Enterprise applications can flexibly switch computer resources according to different business access requirements and flexibly configure the enterprise. Information processing capabilities, greatly reducing information processing costs.

\section{Construction of financial computing service center based on cloud computing}

Internet technology is widely used in enterprises, and networking provides a technical foundation for companies to collect various types of big data. Based on the maturity of big data analysis technology, research and build and develop cloud computing financial shared service center services.

\subsection{Finance cloud management structure}

Finance cloud is the application of cloud computing technology in the financial sharing service center. In cloud computing, the client and the cloud are two important modules. The client is the port through which the user accesses and obtains information, providing users with accurate information. In the cloud, the structural layer is composed of four layers. The application layer continuously improves services such as guarantee management and fund management. The data management layer provides information support. The network service layer uses network storage, email, and web addresses to improve basic network services. The detailed structure diagram of Finance Cloud is as follows: 


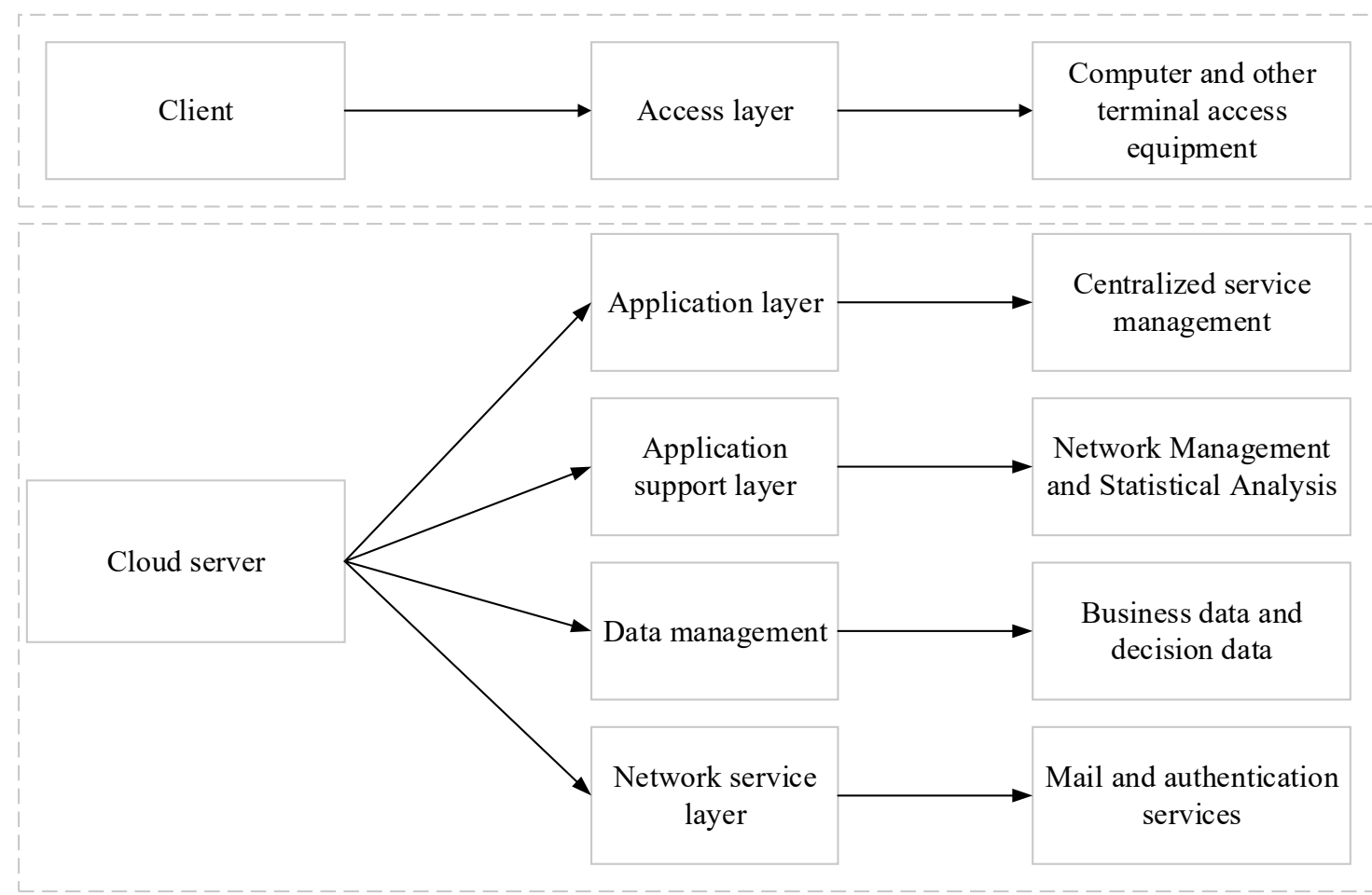

Figure 1. Detailed structure of the financial cloud

\subsection{Model and Construction Strategy of Financial Shared Service Center Based on Cloud Computing}

English units may be used as secondary units (in parentheses). The financial shared service center involves many departments and staffs, and to deal with many matters, it is necessary to make a design plan for the construction model in advance and formulate a construction strategy suitable for its own characteristics. The cloud computing-based financial shared service center construction model roughly includes processes, organization and human resources, information systems, and operations management.

Build strategy. The process of developing normative standards, including activities such as receiving input and generating output. Process design and reengineering include scheme planning and design, test improvement and process optimization; According to different strategic goals of cloud computing financial shared services, rationally arrange and organize organizational structure and staffing, and establish a performance evaluation system; Build an information system; build an integrated operation and management system based on the value chain.

The construction model of corporate financial shared services is shown in Figure 2. 


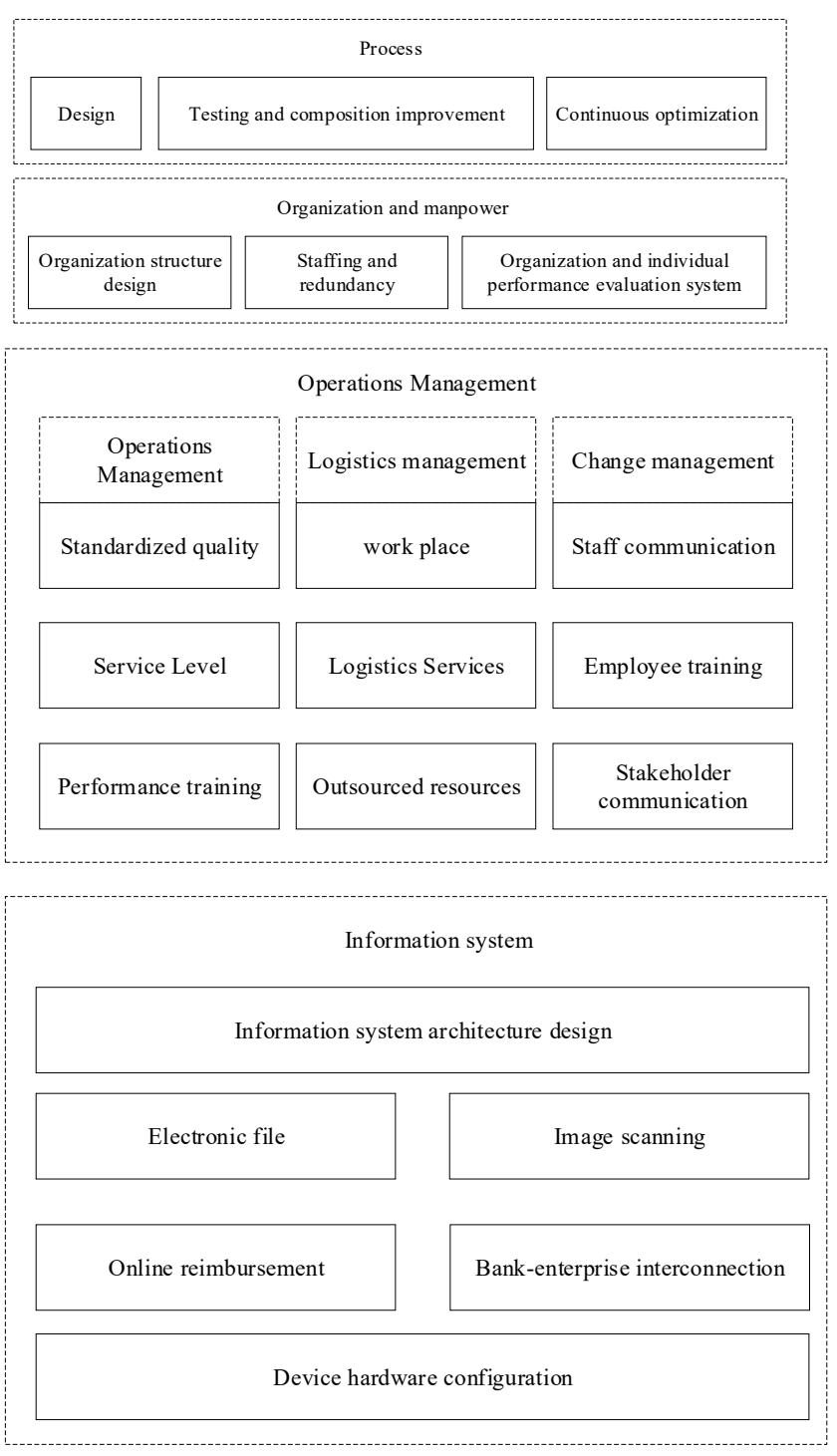

\subsection{Optimization Design of Financial Information System Based on Cloud Computing}

Determine the process design and operation model of the financial shared service center, and build a financial management architecture based on cloud computing. The cloud server includes an application layer, a data management layer, a network service layer, and an application support layer. Among them, the network service layer is responsible for providing network services: the application support layer provides technical support; the data management layer is responsible for data classification and storage; the application layer provides services such as financial accounting and fund management. The user accesses the financial information system through the client, obtains the required information, and interacts with the cloud for financial information operations.

The cloud computing-based financial shared service center mainly applies information system architecture in three aspects: operation management, accounting, management control and auxiliary accounting. Among them, the accounting remains unchanged, and the fund management system and expense reimbursement procedures are updated. In terms of system interface, it is important to build the relationship between personnel and finance, and realize the cost of human resources. The information system architecture of the financial shared service center is shown in Figure 3.

Figure 2. Enterprise cloud computing financial shared service construction model

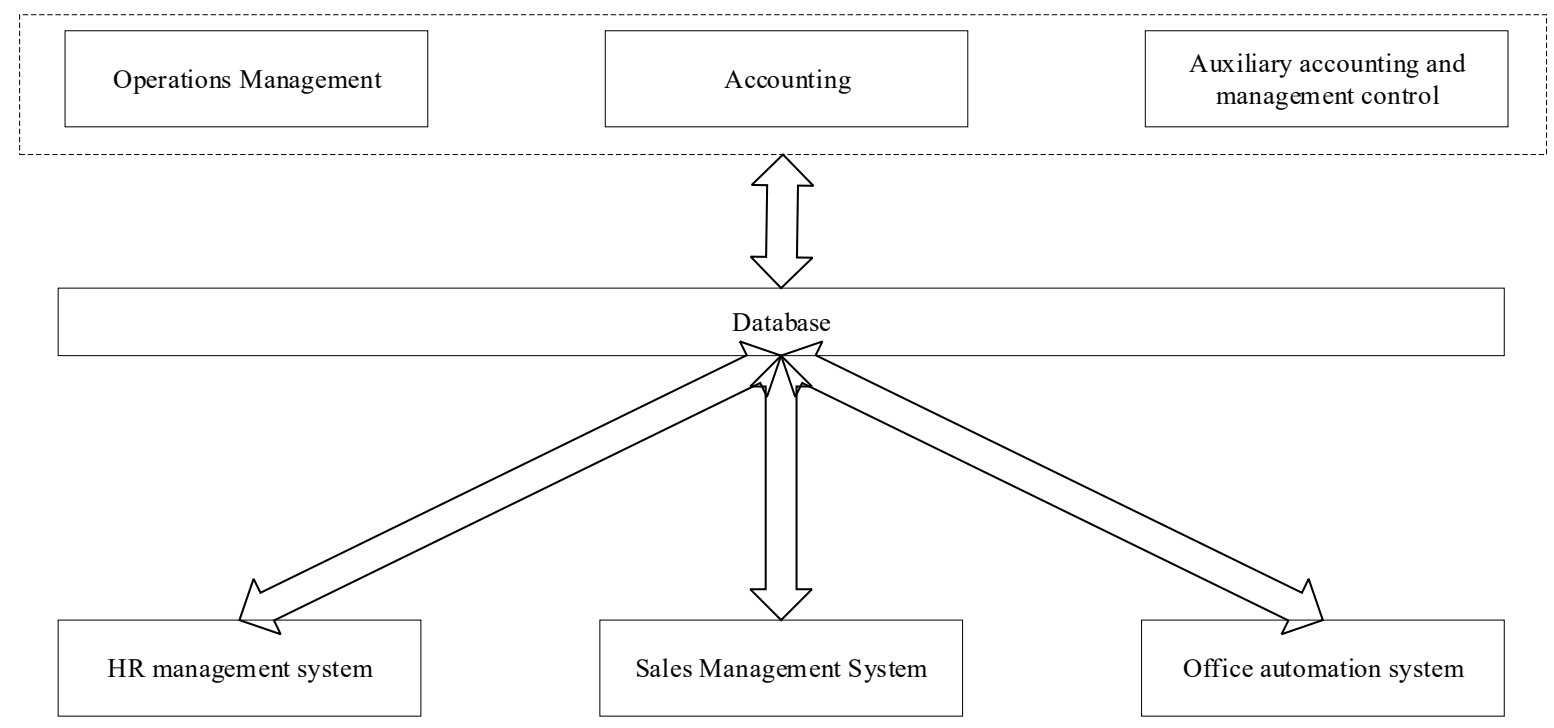

Figure 3. Cloud-based financial sharing center information system architecture 


\subsection{Apply cloud computing to enhance financial data integration and sharing}

With powerful computing and storage capabilities, cloud computing can provide services in a timely manner according to user needs. Cloud computing is the foundation for building and enhancing financial sharing, IT storage capacity, data center facilities, security and software applications.
Cloud computing has powerful storage capabilities and data processing capabilities. Enterprises purchase cloud computing service storage and data processing technologies according to their actual conditions and needs. The more automated the financial information system is, the more financial cloud services can be provided to users. With the improvement of collaboration capabilities, human-driven services are transmitted to the cloud by establishing standardized interfaces. The location of the interface of the financial sharing service center is shown in Figure 4.

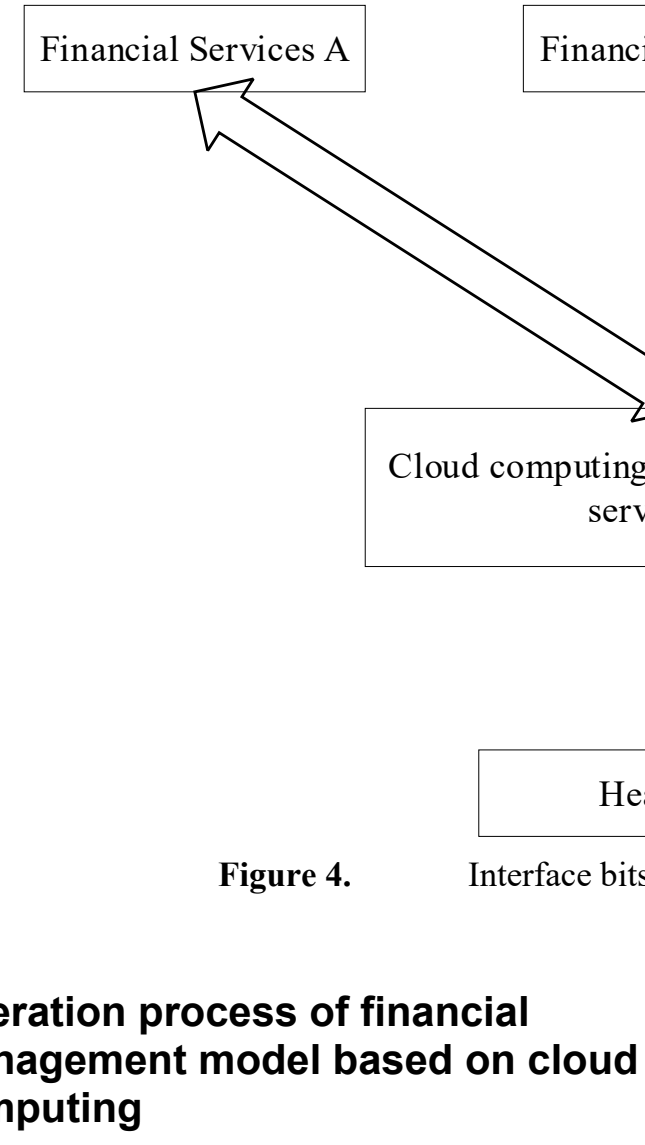

According to the theory of cloud computing, relying on the management system, the collected business data is transmitted to the cloud, and the original files are decomposed according to the review requirements. Finally, vouchers and reports are automatically generated and output. The operation process mainly includes three parts: cloud collection, cloud processing and cloud products.

Cloud collection. In order to receive business data that reflects the actual occurrence of economic activity, data should be collected from within the enterprise and transmitted to the cloud.

Cloud processing. Complete the classification, screening, storage and transfer of business data.

Cloud products. After cloud processing, the cloud platform covers a large number of element information, as well as traditional accounting vouchers. The output cloud products mainly include vouchers for the accounting of corporate fund receipts and payments, daily financial management vouchers and accounting statements; individual reports and consolidated statements; providing users with various financial indicators and data analysis. Figure 5 shows the overall operation process of a cloud-based financial shared service center. 


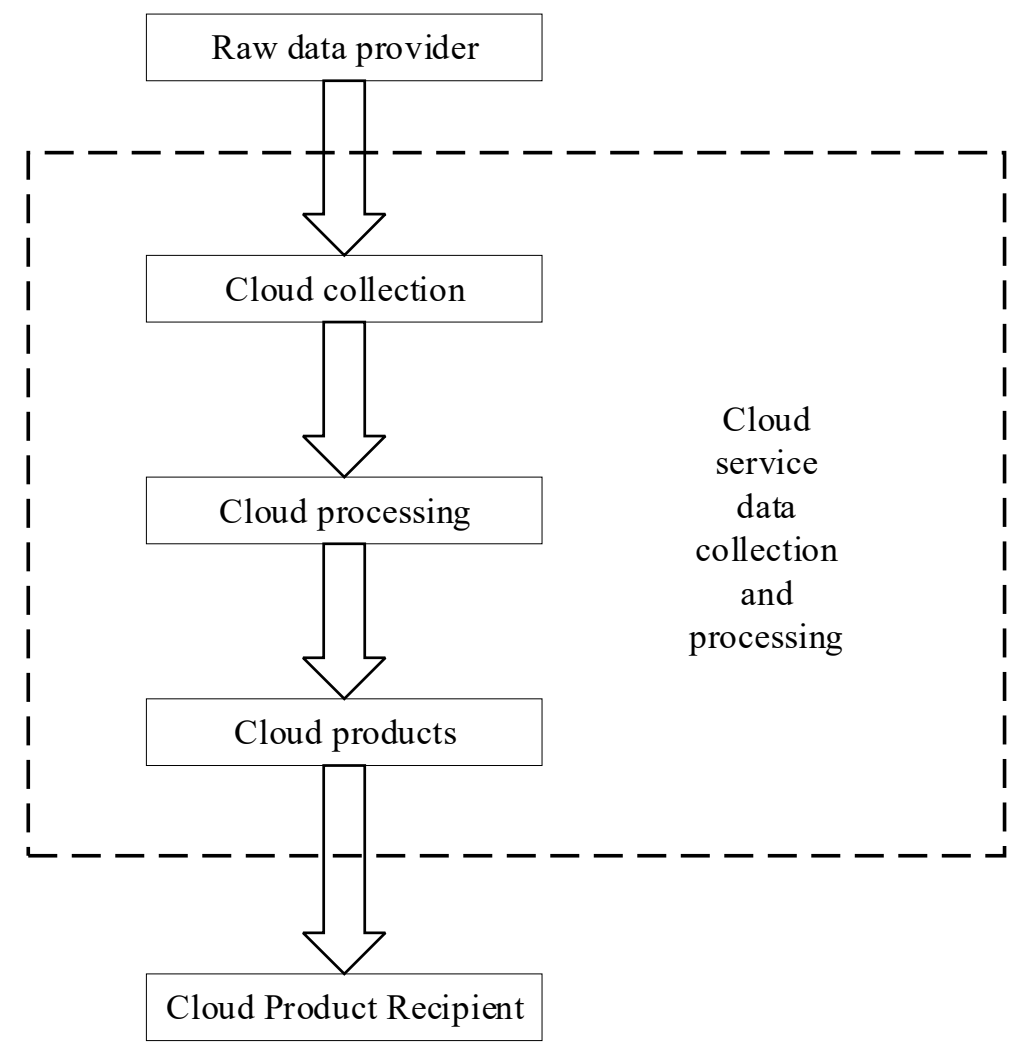

Figure 5. Cloud-based financial shared service center overall operation process

\section{Conclusion}

The use of cloud computing can promote the construction of financial shared service centers. With the development of computer information technology, cloud computing-based financial shared service centers can be perfectly combined with high technology. In the future, the financial shared service model will present a diversified, efficient and sustainable development trend. Based on cloud computing technology, it is an important task for modern enterprises to build an enterprise financial shared service center and study the financial management model that is suitable for the development of the times. Cloud computing technology is maturing and is widely used in various industries. Enterprises rent cloud services to reduce the basic investment in financial sharing; adopt cloud storage to reduce the cost of information storage; use cloud computing to improve the performance of information systems and make financial sharing service centers more powerful.

\section{References}

1. Yang Fuyi. Discussion on the concept of cloud computing and related terms [J]. Chinese Science and Technology Glossary. 2018, (10): 47-51.

2. Cai Hui. The impact of financial sharing on the performance of multinational corporations in the era of big data $[\mathrm{J}]$. Cooperative Economy and Science and Technology, 2017 (2): 162.
3. Cheng Ping. Fund Management of Group A Based on Financial Shared Service Model under Big Data [J] . Friends of Accounting, 2017 (6): 123.

4. Fan Zhiying.The Construction and Application of Financial Sharing Platform under the Background of "Smarter Moving Cloud" —_ TCL Group Co., Ltd. as an Example $[\mathrm{J}]$. Accounting and Communications, 2019 (04): 111-115.

5. Lei Wanyun et al. Cloud ComputingTechnology, Platform and Application Cases [M]. Beijing: Tsinghua University Press, 2011: 36-89.

6. Cheng Ping, Zhao Jinglan. Performance Management of Financial Sharing Center Based on Cloud Accounting in the Era of Big Data[J]. Friend of Accounting, 2017 (4): 130-133.

7. Huang Zhefang. Research on the Construction of Financial Shared Service Center [D]. Xiamen University. 2014, (04).

8. Gao Jingwen. Research on financial transformation problems and countermeasures based on financial shared services [D]. Capital University of Economics. 2017, (06).

9. He Yongli. Application of cloud computing in the construction of financial shared service center [J]. Accounting and Communications, 2016 (31).

10. Wang Yunyun, $\mathrm{Hu}$ Benyuan. Research on the Construction Process of Financial Shared Service Center [J]. China Accounting Monthly, 2017 (1): 34-37. 